\title{
Validation of energy requirement references for exclusively breast-fed infants
}

\author{
Susan B. Nielsen ${ }^{1 *}$, Jonathan C. K. Wells ${ }^{2}$, Mary S. Fewtrell ${ }^{2}$, Simon Eaton ${ }^{3}$, James Grinham ${ }^{2}$ \\ and John J. Reilly ${ }^{4}$ \\ ${ }^{1}$ University of Glasgow, School of Medicine, Centre of Population and Health Sciences, Yorkhill Hospitals, \\ Tower 1st Floor, Glasgow G3 8SJ, Scotland, UK \\ ${ }^{2}$ UCL Institute of Child Health, Childhood Nutrition Research Centre, London, UK \\ ${ }^{3}$ Department of Surgery, UCL Institute of Child Health, London, UK \\ ${ }^{4}$ University of Strathclyde, Physical Activity and Health Research Group, School of Psychological Sciences \\ and Health, Glasgow, UK
}

(Submitted 11 February 2012 - Final revision received 3 August 2012 - Accepted 6 August 2012 - First published online 13 November 2012)

\begin{abstract}
In paediatric practice, mean reference energy requirements for groups are often used to predict individual infant energy requirements. References from the FAO/WHO/United Nations University are based on infants not fed according to the current infant feeding recommendations. The objective of the present study was to measure total energy expenditure (TEE) and determine energy requirements using criterion methods, and validate the use of TEE prediction equation and mean energy requirement references for predicting individual TEE and energy requirements, respectively, in infants who were exclusively breast-fed (EBF) to 6 months of age. EBF infants were included from Greater Glasgow for measurements at 3.5 ( $n$ 36) and 6 ( $n$ 33) months of age. TEE was measured using doubly labelled water and energy requirements were determined using the factorial approach. TEE and energy requirements were also predicted using equations based on body weight. Relationships between criterion methods and predictions were assessed using correlations. Paired $t$ tests and Bland-Altman plots were used to assess agreement. At the population level, predicted and measured TEE were similar. The energy requirement reference significantly underestimated energy requirements by $7.2 \%$ at 3.5 months at the population level, but there was no bias at 6 months. Errors at individual levels were large and energy requirements were underestimated to a larger extent for infants with higher energy requirements. This indicates that references presently used in clinical practice to estimate energy requirements may not fully account for the different growth pattern of EBF infants. More studies in infants EBF to 6 months of age are needed to understand how growth of EBF infants influences energy requirements.
\end{abstract}

Key words: Energy metabolism: Exclusive breast-feeding: Growth: Infant health: Nutritional requirements

The WHO recommends exclusive breast-feeding (EBF) for the first 6 months of life, with EBF defined as giving only breast milk $^{(1,2)}$. EBF is deemed adequate to fulfil infant energy requirements for the first 6 months, although empirical evidence is limited for EBF infants beyond 3 months of age $^{(3-5)}$. Our recent study in well-supported women found adequate breast milk energy intake during 6 months of $\mathrm{EBF}^{(6)}$, and this was also confirmed in a recent randomised controlled trial in Iceland ${ }^{(7)}$, but it needs to be confirmed in other populations. Infant energy requirements are the sum of total energy expenditure (TEE) and energy stored in growth. TEE includes the energy needs for basal metabolism, diet-induced thermogenesis and physical activity, and is influenced largely by age, sex and body size ${ }^{(8)}$. Growth is a sensitive indicator of whether energy requirements are met. Meeting energy requirements is important as both over- and under-nutrition in infancy may impair long-term health ${ }^{(9)}$.

References for human energy requirements published by the FAO, WHO and the United Nations University (UNU) are prescriptive at a population level to support and maintain health and good nutritional status, and they are frequently cited worldwide ${ }^{(10)}$. For infants, the criterion method for determining energy requirements is the factorial approach, which is the sum of TEE, measured by doubly labelled water, and an estimate of energy stored in growth. Such data were used to derive mean energy requirements per $\mathrm{kg}$ body weight for separate age groups, sexes and feeding modes (breast-fed or formula-fed) ${ }^{(10)}$. In the absence of a

Abbreviations: EBF, exclusive breast-feeding; FFM, fat-free mass; FM, fat mass; TEE, total energy expenditure; UNU, United Nations University. 
practical alternative, these references are often used in clinical practice for the prediction of energy requirements of individual infants based on their body weight. However, data for the group of breast-fed infants were derived from infants who were not EBF according to the present WHO recommendations. Feeding mode affects TEE as well as body composition and growth in infancy ${ }^{(11-18)}$, and these effects are likely to influence energy requirements. Therefore, there is a need for more data on energy requirements in EBF infants. With many resources currently being invested in the promotion of initiation, duration and exclusivity of breast-feeding, it is also important to know if the mean reference for energy requirements per kg body weight is valid to use for infants who are EBF according to the current infant feeding recommendations. Therefore, the primary aims of the present study were to:

(1) Measure TEE of infants who were EBF, as defined by the WHO, until 6 months of age, and determine energy requirements using the criterion method (the factorial approach of measured TEE plus energy stored in growth).

(2) Compare measured TEE with TEE predicted from body weight using the equation for breast-fed infants published by the $\mathrm{FAO} / \mathrm{WHO} / \mathrm{UNU}^{(10)}$.

(3) Assess the accuracy of predicting energy requirements at the individual level, using mean reference energy requirements per kg body weight ${ }^{(10)}$ by comparison with determined energy requirements from the criterion method.

\section{Methods}

\section{Study design and participants}

The First-Feed study was a longitudinal observational study on milk intake, energy balance and growth in EBF infants aged from 3.5 to 6 months, described in detail elsewhere ${ }^{(6,19)}$. In brief, healthy participants, who indicated a determination to breast-feed according to the WHO recommendation, were recruited from the National Health Service clinics and local breast-feeding groups in Greater Glasgow, Scotland. Mother-infant pairs were included for the first time point of measurements at 15-16 weeks of age, if they were exclusively breast-feeding, and then followed up to the second time point at 24-25 weeks of age. All measurements were performed in the field during home visits by one researcher (S. B. N.). The present study was conducted according to the guidelines laid down in the Declaration of Helsinki and all procedures involving human subjects/patients were approved by the National Health Service Research Ethics Committee of Greater Glasgow and Clyde Primary Care Division (ref. no. 07/S0701/15). Written informed consent was obtained from all participants.

\section{Anthropometric measurements}

Body weight was measured on a digital scale with an increment of $20 \mathrm{~g}$ (Seca 835; Medical Scales and Measuring Systems Seca Ltd). Length was measured to the last completed millimetre on a measuring board (Kiddimetre; Raven Equipment) and reported as a mean of three readings.

\section{Measurement of total energy expenditure}

TEE was measured using the doubly labelled water method as a mean value over $7 \mathrm{~d}$, as described elsewhere ${ }^{(6)}$. The doubly labelled water method is the criterion method for measuring TEE. In brief, doubly labelled water was purchased as ready mixed sterilised doubly labelled water containing $>99.9$ atom $\%{ }^{2} \mathrm{H}_{2} \mathrm{O}$ and $10 \cdot 4$ atom $\% \mathrm{H}_{2}{ }^{18} \mathrm{O}$ (Rotem Industries Limited), and the dose required, which was $2.6 \mathrm{~g} / \mathrm{kg}$ body weight, was administered to the infant through a $5 \mathrm{ml}$ syringe, a feeding-tube or through the infant's own feeding bottle ${ }^{(19)}$. Dosing equipment was measured on a precision scale (model BA 310P; Sartorius) before and after dose administration to calculate the actual amount of dose consumed. Urine samples were collected from the infants by placing cotton wool in the nappies ${ }^{(20)}$, and analysed for background abundance levels (pre-dose) and isotopic enrichment (postdose) by isotope ratio mass spectrometry equilibration expressed relative to Vienna - Standard Mean Ocean Water $^{(21)}$, as described previously ${ }^{(22)}$. Dilution spaces and isotope elimination rates were calculated by the back extrapolation method $^{(23)}$, using a pre-coded spreadsheet ${ }^{(24)}$ to derive values of body composition (fat mass; FM and fat-free mass; FFM) and TEE, as described previously ${ }^{(6)}$. TEE was calculated from $\mathrm{CO}_{2}$ production rate as:

$$
r_{\mathrm{CO}_{2}}=\frac{\left(N_{\mathrm{O}} \times k_{\mathrm{O}}\right)}{2 \times f_{3}}-\frac{\left(N_{\mathrm{D}} \times K_{\mathrm{D}}\right) \times\left(\left(X \times f_{2}\right)+1-X\right)}{2 \times f_{3} \times\left(\left(X \times f_{1}\right)+1-X\right)},
$$

where $N_{\mathrm{O}}$ and $N_{\mathrm{D}}$ are the ${ }^{18} \mathrm{O}$ and ${ }^{2} \mathrm{H}$ dilution spaces, respectively, $k_{\mathrm{O}}$ and $k_{\mathrm{D}}$ are the ${ }^{18} \mathrm{O}$ and ${ }^{2} \mathrm{H}$ elimination rate constants, respectively, $f_{1}$ is the fractionation factor for ${ }^{2} \mathrm{H}$ between vapour and liquid (0.93), $f_{2}$ is the fractionation factor for ${ }^{18} \mathrm{O}$ between vapour and liquid (0.99), $f_{3}$ is the fractionation factor for ${ }^{18} \mathrm{O}$ between $\mathrm{CO}_{2}$ and water (1.04) and $X$ is the proportion of water subject to fractionation (assumed to be $0 \cdot 15$ ). Oxygen consumption was predicted from $\mathrm{CO}_{2}$ production rate using an assumed respiratory quotient of 0.85. TEE was calculated using Weir's equation ${ }^{(25)}$. In order to ensure that only high-quality isotopic data were included, isotope space ratio had to be within 1.010 to 1.090 and the estimated total error on energy expenditure had to be $<10 \%$.

\section{Energy requirements determined using the factorial approach}

For the EBF infants, a sample who grew normally relative to the WHO Child Growth Standards ${ }^{(26)}$, the infant energy requirements were determined using the criterion method of adding measured TEE to estimated energy stored in growth (the factorial approach). Energy stored in growth $(\mathrm{kJ} / \mathrm{d})$ was calculated from weight gain over the $7 \mathrm{~d}$ of the TEE measurement, as described previously ${ }^{(6)}$. In brief, data on total body water (TBW) on day 0 were calculated as the ${ }^{18} \mathrm{O}$ dilution space divided by $1 \cdot 01^{(27)}$. FFM on day 0 was calculated from TBW using an age- and sex-specific factor of hydration 
of $\mathrm{FFM}^{(28)}$. FM on day 0 was then calculated as body weight minus FFM. Weight gain over the $7 \mathrm{~d}$ was assumed to have a linear increase in the proportions of $\mathrm{FM}$ and $\mathrm{FFM}^{(29)}$. Gain in FM ( $g$ ) was calculated directly as the difference in FM between day 0 and day 7. Gain in FFM was corrected for age- and sex-specific changes in hydration and in the proportion of FFM, i.e. protein, using regression equations derived from data on the reference child ${ }^{(28)}$, resulting in a value of protein gain $(\mathrm{g})$. Finally, the energy stored as fat and protein was calculated, assuming an energy value of $38.7 \mathrm{~kJ} / \mathrm{g}$ for fat and $23.6 \mathrm{~kJ} / \mathrm{g}$ for protein.

\section{Total energy expenditure prediction using the FAO/WHO/ United Nations University equation for breast-fed infants}

TEE was predicted from the equation published by the FAO/ WHO/UNU for breast-fed infants ${ }^{(10)}$ :

$$
\begin{aligned}
& \text { TEE }(\mathrm{kJ} / \mathrm{d})=-635+388 \times \text { body weight }(\mathrm{kg}) \\
& \quad \mathrm{SEE}=453 \mathrm{~kJ} / \mathrm{d}
\end{aligned}
$$

where SEE is standard error of the estimate.

\section{Energy requirements prediction using a multiplier of the mean FAO/WHO/United Nations University reference}

Individual infant energy requirements were predicted from the mean energy requirements per $\mathrm{kg}$ body weight for breast-fed infants published by the $\mathrm{FAO} / \mathrm{WHO} / \mathrm{UNU}^{(10)}$ using the values $355 \mathrm{~kJ} / \mathrm{kg} \times \mathrm{d}$ at the first time point ( 3.5 months) and $330 \mathrm{~kJ} / \mathrm{kg} \times \mathrm{d}$ at the second time point $(6 \text { months })^{(10)}$.

\section{Statistical methods}

Power for the present study was fixed by the First-Feed study, which was powered to detect changes in metabolisable milk intake between 3.5 and 6 months of age during $\mathrm{EBF}^{(6)}$. A study investigating energy requirements by Butte et al. ${ }^{(18)}$ included seventy-six infants (forty breast-fed infants), and a review of similar studies by Butte ${ }^{(8)}$ indicated the typical sample size to be about forty infants. A post hoc power calculation, based on the results from the first time point, for a two-tailed test with a mean paired difference of 178 (SD 221$) \mathrm{kJ} / \mathrm{d} ; \Delta$ of 0.81 (SD 178/221); and with a power of 0.9 at the $<0.05$ significance level, we would need 20-25 paired observations.

The outcome measures were the variables of the criterion methods of measured TEE (from the doubly labelled water method) and determined energy requirements (from the factorial approach), as well as variables of predicted TEE and predicted energy requirements. Measured and predicted TEE, as well as determined and predicted energy requirements, were compared using paired $t$ tests, where the mean difference between the criterion method and the prediction indicates the size of bias, while the standard deviation of the mean difference indicates how different the two methods can be for the majority of the population ${ }^{(30)}$ (of exclusively breast-fed infants). Pearson correlations were performed to explore the relationship between criterion methods and predictions. The agreement between criterion methods and predictions was assessed using Bland-Altman plots ${ }^{(30)}$ of the difference between criterion and prediction $v$. the mean of the criterion and prediction for each data point, and the mean $\pm 2 \mathrm{sD}$ of the differences was identified as bias \pm limits of agreement. This was done for both measured and predicted TEE, and for determined and predicted energy requirements. Normality was ascertained by Shapiro-Wilk's test and statistical tests were performed using PASW statistics ${ }^{\circledR} 18$ (SPSS Inc.).

\section{Results}

\section{Participant characteristics}

Characteristics of mothers and infants are shown in Table 1, and have also been described elsewhere ${ }^{(6)}$. Of fifty mother-infant pairs included, forty-seven mothers completed the study. Six had introduced complementary foods by the second time point, while forty-one mother-infant pairs were EBF as defined by the $\mathrm{WHO}^{(2)}$. The median socio-economic status categorised by Scottish Index of Multiple Deprivation decile (where 1 is the poorest decile) was 8 (range $2-10$ ) for EBF infants ( $n$ 41). The majority of participants (thirty six, 88\%) were white Europeans. The infants showed normal growth relative to the WHO Child Growth Standards ${ }^{(26)}$, with a mean weight-for-age $z$-score of 0.06 (SD 0.92) and 0.08 (SD 0.92) at the first and second time points, respectively ${ }^{(6)}$.

Infant characteristics, growth, body composition, TEE and predicted variables are summarised in Table 2. At the first time point, eleven data points were lost due to unsuccessful dose administrations (infants not able to consume the doubly labelled water or having reflux) or analytical problems (isotope analyses not complying with quality criteria stated earlier), and at the second time point, six infants were not $\mathrm{EBF}$ and a further eight data-points were lost due to unsuccessful dose administrations or analytical problems. The analytical problems were not necessarily problems with the isotope ratio mass spectrometry itself, but had resulted in

Table 1. Characteristics of participants

(Mean values and standard deviations; number of participants and

\begin{tabular}{|c|c|c|}
\hline & \multicolumn{2}{|c|}{$\begin{array}{c}\text { Included } \\
\text { participants }(n 41)\end{array}$} \\
\hline & $n$ & $\%$ \\
\hline \multicolumn{3}{|c|}{ Self-reported educational attainment } \\
\hline Higher grades* & 1 & 2 \\
\hline College & 4 & 10 \\
\hline University & 36 & 88 \\
\hline \multicolumn{3}{|l|}{ Parity } \\
\hline First child & 29 & 71 \\
\hline Second child & 9 & 22 \\
\hline Third child & 3 & 7 \\
\hline \multicolumn{3}{|c|}{ Maternal age (years) } \\
\hline Mean & \multicolumn{2}{|c|}{33.5} \\
\hline SD & \multicolumn{2}{|c|}{$4 \cdot 1$} \\
\hline \multicolumn{3}{|c|}{ Infant birth weight $(\mathrm{kg})$} \\
\hline Mean & \multicolumn{2}{|c|}{$3 \cdot 64$} \\
\hline SD & \multicolumn{2}{|c|}{0.37} \\
\hline
\end{tabular}
percentages)

*Equivalent to 12 years of school education. 
Table 2. Infant characteristics and energy balance variables for first and second time points $\dagger$

(Mean values and standard deviations, $n$ 26)

\begin{tabular}{|c|c|c|c|c|c|c|c|c|c|c|c|c|}
\hline & \multicolumn{6}{|c|}{ First time point } & \multicolumn{6}{|c|}{ Second time point } \\
\hline & \multicolumn{2}{|c|}{ Boys (n 17) } & \multicolumn{2}{|c|}{ Girls (n 19) } & \multicolumn{2}{|c|}{ All $(n 36)$} & \multicolumn{2}{|c|}{ Boys (n 16) } & \multicolumn{2}{|c|}{ Girls (n17) } & \multicolumn{2}{|c|}{ All $(n 33)$} \\
\hline & Mean & SD & Mean & SD & Mean & SD & Mean & SD & Mean & SD & Mean & SD \\
\hline \multicolumn{13}{|l|}{ Infant characteristics } \\
\hline Age (weeks) & $15 \cdot 2$ & $1 \cdot 1$ & $15 \cdot 7$ & $1 \cdot 6$ & $15 \cdot 4$ & 1.4 & $24 \cdot 4$ & 1.5 & $24 \cdot 8$ & $1 \cdot 0$ & $26 \cdot 6$ & $1 \cdot 3$ \\
\hline Body weight (kg) & $6 \cdot 81$ & 0.77 & $6 \cdot 41$ & 0.69 & $6 \cdot 60$ & 0.74 & $7 \cdot 88$ & 0.81 & 7.46 & 0.83 & $7 \cdot 66$ & 0.83 \\
\hline Length $(\mathrm{cm})$ & $62 \cdot 4$ & $2 \cdot 1$ & $61 \cdot 3$ & $2 \cdot 2$ & $61 \cdot 8$ & $2 \cdot 2$ & $66 \cdot 3$ & $2 \cdot 0$ & 65.5 & $2 \cdot 3$ & $65 \cdot 9$ & $2 \cdot 2$ \\
\hline Weight-for-age (z-scores) & 0.12 & $1 \cdot 17$ & 0.15 & 0.96 & 0.14 & 1.05 & 0.39 & 0.98 & 0.24 & 0.84 & 0.31 & 0.90 \\
\hline Length-for-age (z-scores) & -0.13 & 1.08 & 0.11 & 0.92 & -0.01 & 0.99 & -0.36 & 1.02 & 0.06 & 0.98 & -0.14 & 1.01 \\
\hline Weight-for-length (z-scores) & -0.02 & 1.03 & 0.13 & 0.84 & 0.06 & 0.92 & 0.03 & 0.99 & 0.14 & $0 \cdot 88$ & 0.08 & 0.92 \\
\hline \multicolumn{13}{|l|}{ Body composition } \\
\hline FFM $(\mathrm{kg})$ & 4.92 & 0.55 & $4 \cdot 64$ & 0.46 & $4 \cdot 77$ & 0.52 & $5 \cdot 60$ & 0.62 & $5 \cdot 22$ & 0.58 & $5 \cdot 40^{*}$ & 0.62 \\
\hline $\mathrm{FM}(\mathrm{kg})$ & $1 \cdot 81$ & 0.39 & 1.69 & 0.37 & $1 \cdot 74$ & 0.38 & $2 \cdot 21$ & 0.51 & $2 \cdot 19$ & 0.39 & $2 \cdot 20^{*}$ & 0.44 \\
\hline FM (\%) & $26 \cdot 8$ & $4 \cdot 4$ & $26 \cdot 5$ & $4 \cdot 2$ & $26 \cdot 7$ & $4 \cdot 2$ & $28 \cdot 2$ & $5 \cdot 0$ & $29 \cdot 6$ & $3 \cdot 6$ & $28 \cdot 9^{\star}$ & $4 \cdot 3$ \\
\hline \multicolumn{13}{|l|}{ Growth } \\
\hline Weight gain $(g / d)$ & $25 \cdot 6$ & $13 \cdot 6$ & $22 \cdot 9$ & $12 \cdot 0$ & $24 \cdot 2$ & $12 \cdot 7$ & $20 \cdot 9$ & $15 \cdot 3$ & $16 \cdot 0$ & $12 \cdot 6$ & $18 \cdot 4$ & $14 \cdot 0$ \\
\hline FFM gain $(g / d)$ & $12 \cdot 6$ & $9 \cdot 6$ & $9 \cdot 6$ & $8 \cdot 1$ & $11 \cdot 0$ & $8 \cdot 8$ & $15 \cdot 1$ & $10 \cdot 1$ & $9 \cdot 1$ & $8 \cdot 7$ & $12 \cdot 0$ & $9 \cdot 7$ \\
\hline Protein gain (g/d) & $2 \cdot 2$ & 1.5 & 1.8 & $1 \cdot 3$ & $2 \cdot 0$ & 1.4 & $2 \cdot 6$ & $1 \cdot 6$ & $1 \cdot 8$ & 1.4 & $2 \cdot 2$ & 1.6 \\
\hline FM gain $(g / d)$ & $13 \cdot 1$ & $4 \cdot 3$ & $13 \cdot 3$ & $4 \cdot 2$ & $13 \cdot 2$ & $4 \cdot 2$ & $5 \cdot 8$ & $5 \cdot 9$ & $6 \cdot 9$ & $4 \cdot 1$ & $6 \cdot 3^{\star}$ & $5 \cdot 0$ \\
\hline Protein stored $(\mathrm{kJ} / \mathrm{d})$ & 53 & 35 & 43 & 31 & 48 & 33 & 62 & 38 & 42 & 34 & 52 & 37 \\
\hline Fat stored $(\mathrm{kJ} / \mathrm{d})$ & 505 & 165 & 513 & 161 & 509 & 161 & 223 & 230 & 265 & 157 & $245^{\star}$ & 194 \\
\hline Energy stored $(\mathrm{kJ} / \mathrm{d})$ & 558 & 198 & 556 & 189 & 557 & 191 & 286 & 261 & 307 & 189 & $297^{\star}$ & 224 \\
\hline TEE $(\mathrm{kJ} / \mathrm{d})$ & 2024 & 340 & 1846 & 173 & 1930 & 276 & 2440 & 480 & 2130 & 249 & $2280^{*}$ & 405 \\
\hline \multicolumn{13}{|l|}{ Predictions } \\
\hline Predicted TEE (kJ/d) & 1968 & 294 & 1818 & 257 & 1889 & 282 & 2398 & 315 & 2233 & 317 & $2313^{*}$ & 322 \\
\hline Predicted $E_{\text {req }}(\mathrm{kJ} / \mathrm{d}) \ddagger$ & 2381 & 269 & 2244 & 235 & 2309 & 258 & 2580 & 268 & 2440 & 270 & 2508 & 274 \\
\hline
\end{tabular}

FFM, fat-free mass; FM, fat mass; TEE, total energy expenditure; $E_{\text {req, }}$ energy requirements.

${ }^{*}$ Mean values were significantly different between the first and second time points tested with paired $t$ tests $(P \leq 0.001)$.

†One extreme outlier (boy) at the second time point resulted in some variables not being normally distributed and resulted in wider variation (high SD) in the summarised data.

Repeating analysis using Mann-Whitney tests did not change any results.

$\ddagger E_{\text {req }}$ predicted as a multiplier of body weight using the mean reference of energy requirements in $\mathrm{kJ} / \mathrm{kg} \times \mathrm{d}$ from the $\mathrm{FAO} / \mathrm{WHO} / \mathrm{United} \mathrm{Nations}$ University ${ }^{(10)}$.

isotope space ratios $<1.010$ or $>1.090$ or an estimated total error on energy expenditure $>10 \%$. This meant that thirtysix and thirty-three data points were available at the first and second time points, respectively.

\section{Comparison of measured total energy expenditure and} total energy expenditure predicted from the FAO/WHO/ United Nations University equation

Measured TEE from the doubly labelled water method and predicted TEE from the equation by the FAO/WHO/UNU ${ }^{(10)}$ were significantly positively correlated at both time points (first and second time points: $r 0.39, P=0.018$ and $r 0.37$, $P=0.035$, respectively) (Table 3 ). There was no significant bias at the population level, and mean paired difference between predicted and measured TEE was - $41(95 \% \mathrm{CI}$ $-146,63) \mathrm{kJ} / \mathrm{d}(P=0.423)$ and $33(95 \% \mathrm{CI}-114,180) \mathrm{kJ} / \mathrm{d}$ $(P=0.649)$ at the first and second time points, respectively. Bland-Altman plots are shown in Figs. 1 and 2 for the two time points. Limits of agreement (bias $\pm 2 \mathrm{SD}$ ) were -657 to $575 \mathrm{~kJ} / \mathrm{d}$ and -795 to $861 \mathrm{~kJ} / \mathrm{d}$ for the first and second time points, respectively. The errors in prediction of TEE were significantly negatively correlated with measured TEE at both time points (first and second time points: $r-0.54$, $P=0.001$ and $r-0.69, P<0.001$, respectively). When the variables of measured and predicted TEE were expressed as tertiles for the first time point, sixteen out of thirty-six (44\%) infants were classified in the correct tertile when comparing

Table 3. Relationship and agreement between criterion methods and predictions for total energy expenditure (TEE) and energy requirements (Mean values and standard deviations)

\begin{tabular}{|c|c|c|c|c|c|c|c|}
\hline & \multicolumn{2}{|c|}{$\begin{array}{l}\text { Pearson } \\
\text { correlation }\end{array}$} & \multicolumn{3}{|c|}{ Paired $t$ test } & \multicolumn{2}{|c|}{$\begin{array}{l}\text { Limits of } \\
\text { agreement }\end{array}$} \\
\hline & $r$ & $P$ & Mean difference & SD & $P$ & Lower $(\mathrm{kJ} / \mathrm{d})$ & Upper $(\mathrm{kJ} / \mathrm{d})$ \\
\hline \multicolumn{8}{|l|}{ First time point $(n 36)$} \\
\hline Measured $v$. predicted TEE $(\mathrm{kJ} / \mathrm{d})^{\star}$ & 0.392 & 0.018 & -42 & 308 & 0.423 & -657 & 575 \\
\hline Determined $v$. predicted energy requirements $(\mathrm{kJ} / \mathrm{d}) \dagger$ & 0.702 & $<0.001$ & -178 & 221 & $<0.001$ & -620 & 264 \\
\hline \multicolumn{8}{|l|}{ Second time point $(n 33)$} \\
\hline Measured v. predicted TEE $(\mathrm{kJ} / \mathrm{d})^{\star}$ & 0.369 & 0.035 & 33 & 414 & 0.649 & -795 & 861 \\
\hline Determined $v$. predicted energy requirements $(\mathrm{kJ} / \mathrm{d}) \dagger$ & 0.428 & 0.013 & -69 & 407 & 0.336 & -883 & 745 \\
\hline
\end{tabular}

* TEE measured by doubly labelled water and predicted using the prediction equation published by the FAO/WHO/United Nations University (UNU) ${ }^{(10)}$.

$\dagger$ Energy requirements determined using the factorial approach and predicted using a mean reference value published by the FAO/WHO/UNU ${ }^{(10)}$ as a multiplier of body weight. 


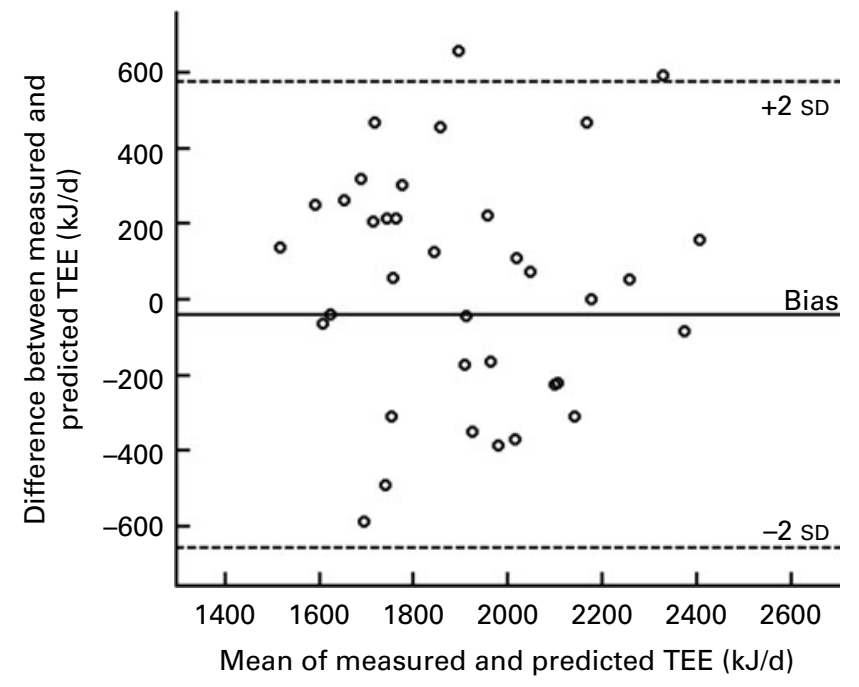

Fig. 1. Bland-Altman plot of the difference between predicted and measured total energy expenditure (TEE) $v$. the mean of predicted and measured TEE for the first time point. Bias is indicated by the full line and limits of agreements are indicated by punctured lines.

predicted TEE with the measured TEE. For the second time point, eighteen out of thirty-three (55\%) infants were correctly classified within their tertile when comparing the predicted with the measured TEE.

\section{Accuracy of predicting energy requirements using the FAO/WHO/United Nations University reference}

There was a significant bias in the prediction of energy requirements using the reference by the $\mathrm{FAO} / \mathrm{WHO} / \mathrm{UNU}^{(10)}$ as a multiplier of body weight at 3.5 months, but not at 6 months. The mean paired differences between determined energy requirements (the criterion method) and predicted energy requirements were $-178(95 \% \mathrm{CI}-253,-104) \mathrm{kJ} / \mathrm{d}$ $(P<0.001)$ and $-69(95 \% \mathrm{CI}-214,75) \mathrm{kJ} / \mathrm{d}(P=0.336)$ at the first and second time points, respectively (Figs. 3 and 4). Limits of agreement were -620 to $264 \mathrm{~kJ} / \mathrm{d}$ and -883 to $745 \mathrm{~kJ} / \mathrm{d}$ at the first and second time points, respectively. Both time points showed significant negative correlation between error and energy requirements (first and second time points: $r-0.56$ and $r-0.80$, respectively, both $P<0.001$ ); hence, energy requirements were underestimated to a larger extent for infants with higher energy requirements. When the variables of determined and predicted energy requirements were expressed as tertiles, twenty-six out of thirty-six (72\%) infants were classified in their correct tertile at the first time point, and at the second time point, twentytwo out of thirty-three (67\%) infants were classified in their correct tertile.

\section{Discussion}

In the present study, the accuracy of prediction of two variables (TEE and energy requirements) was assessed at two time points and across the range of variation in TEE and energy requirements. The ability to detect significant prediction errors in each variable will depend on the study power, on the nature and magnitude of individual biological variation and on the variation between individuals at each time point. We found TEE to be similar at the population level, whether it was measured using doubly labelled water or predicted from the $\mathrm{FAO} / \mathrm{WHO} / \mathrm{UNU}$ equation for $\mathrm{TEE}^{(10)}$. Additionally, we found a large and statistically significant bias as well as large errors at 3.5 months of age, when energy requirements were predicted from a simple multiplier of body weight based on the reference by the FAO/WHO/ $\mathrm{UNU}^{(10)}$. The predicted energy requirements revealed an underestimation bias of $7.2 \%$ at the population level compared with the determined energy requirement using the criterion method. There was no bias at 6 months of age, but large errors at the individual level remained. Therefore, the present study shows that using this simple multiplier of body weight for predicting infant energy requirements is biased in EBF infants at 3.5 months, and has too large errors to be used with confidence at an individual level (e.g. in clinical practice), as shown by wide limits of agreement, in EBF infants at both 3.5 and 6 months of age.

Predicting TEE at the individual level is notoriously difficult due to the many factors that influence TEE, which are not taken into account in prediction equations, and due to errors in the measurement of TEE. However, these errors are expected to level out at the population level, and when considered at this level, the equation published by the FAO/ WHO/UNU seemed sufficiently adequate for predicting TEE in EBF infants. Previous studies have shown similar problems in predicting TEE in other populations ${ }^{(31-33)}$. Furthermore, studies have found body size alone to be a poor predictor of TEE during infancy ${ }^{(34)}$, and that FFM and behavioural factors together accounted for $46 \%$ of the variation in TEE in children aged 9 and 12 months $^{(35)}$. One study suggested

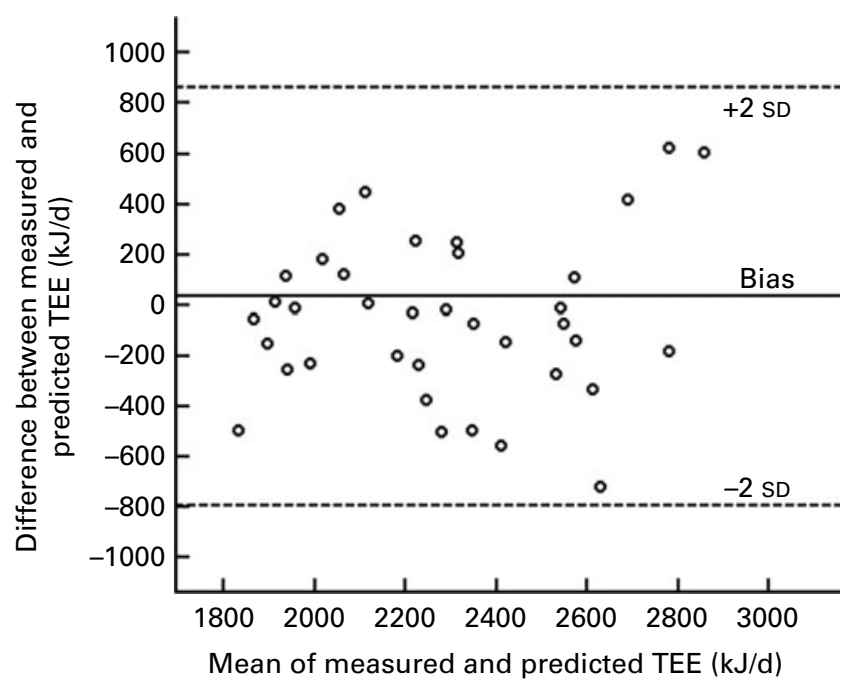

Fig. 2. Bland-Altman plot of the difference between predicted and measured total energy expenditure (TEE) $v$. the mean of predicted and measured TEE for the second time point. Bias is indicated by the full line and limits of agreements are indicated by punctured lines. One data point (extreme outlier; difference between measured and predicted TEE was $1493 \mathrm{~kJ} / \mathrm{d}$, mean of measured and predicted TEE was $2703 \mathrm{~kJ} / \mathrm{d}$ ) was removed for graphical purposes. 


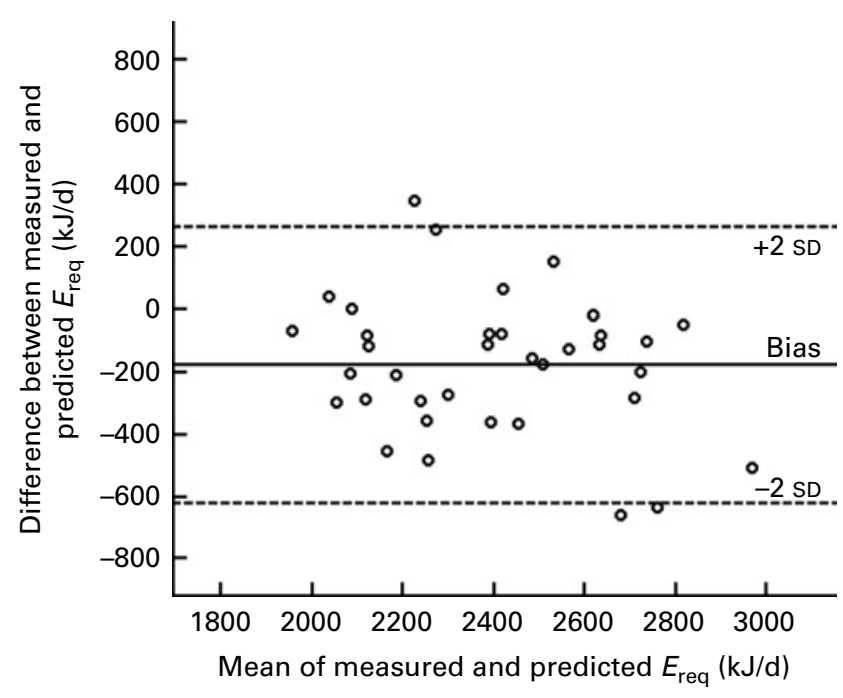

Fig. 3. Bland-Altman plot of the difference between predicted energy requirements ( $E_{\text {req }}$, using a simple multiplier of body weight) and determined $E_{\text {req }}$ (using the factorial approach) $v$. the mean of predicted and determined $E_{\text {req }}$ for the first time point. Bias is indicated by the full line and limits of agreements are indicated by punctured lines.

improvement in the error of prediction equations for RMR by computing an average from several independently derived prediction equations ${ }^{(36)}$. The 'wisdom of crowds' approach confirmed the weakness of using predictions based on one or few factors ${ }^{(36)}$, but more independent equations are needed for infant TEE before it can be implemented in clinical practice.

The references for infant energy requirements published by the $\mathrm{FAO} / \mathrm{WHO} / \mathrm{UNU}$ are meant to be used at the population level, but are commonly used for predicting energy requirements at the individual level in clinical practice. We found that using these references as a simple multiplier of body weight significantly underestimated energy requirements for EBF infants at 3.5 months of age at the population level, whereas there was no bias at 6 months. As there was no bias in predicting TEE, it is possible that the equations tested in the present study for predicting energy requirements in infancy do not sufficiently take into account the different growth patterns in EBF infants ${ }^{(12-14,16)}$. Growth rate is slower at 6 months than at 3 months of age, and constitutes a smaller part of infant energy requirements. Butte et al. ${ }^{(18)}$ performed a thorough study and were able to generate regression equations for infant energy requirements that took feeding mode into account as a factor in determining energy requirements, although the breast-fed infants in that study were not fed according to the current infant feeding recommendation. When using the factorial approach to determine energy requirements, the estimation of energy stored in growth is prone to error. As growth varies between formula-fed and breast-fed infants, and as EBF is now recommended to 6 months of age, there is a great need to expand the evidence base of energy stored in growth in EBF infants in order to more accurately estimate the energy requirements in this group of infants.
The present study had a number of limitations. The precision of the estimate of energy stored in growth relies on repeated measurements of weight to determine weekly weight gain, and we observed a relatively wide variation in the data on weight gain. This could partly be due to lack of precision of the scale for measuring weight; however, more precise weighing scales may not be suitable for use in the field, as this will affect their calibration. More importantly, the daily fluctuations in body weight are much greater than the weekly weight gain for each infant, particularly at 6 months, and as it was not possible to standardise the weighing relative to, for example, feeding times, this might have introduced an extra factor of imprecision in the estimate of energy stored in growth. We also observed a larger variation in data of measured TEE as well as estimate of energy stored in growth at 6 months of age, than at 3.5 months, partly due to an outlier in the dataset and partly due to increased variability in factors influencing TEE, for example, physical activity, which was not measured in the present study. Subsequently, errors between predicted and determined energy requirements were larger at 6 months, reducing the power to detect any bias. The application of the doubly labelled water method to infants also introduces a factor of imprecision to this criterion method, because the precision of dose administration is compromised (relative to children and adults) when infants do not comply with the procedure. This can cause spills of doubly labelled water and, in a worse case, a missed data-point if the dose administration has to be abandoned. The imprecision caused by spills has been discussed elsewhere ${ }^{(19)}$. Even though there were no differences between infants with successful and unsuccessful measurements (data not shown), the loss of data points reduced the power of the present study. Finally, the infants were well-nourished and living in a relatively affluent envi-

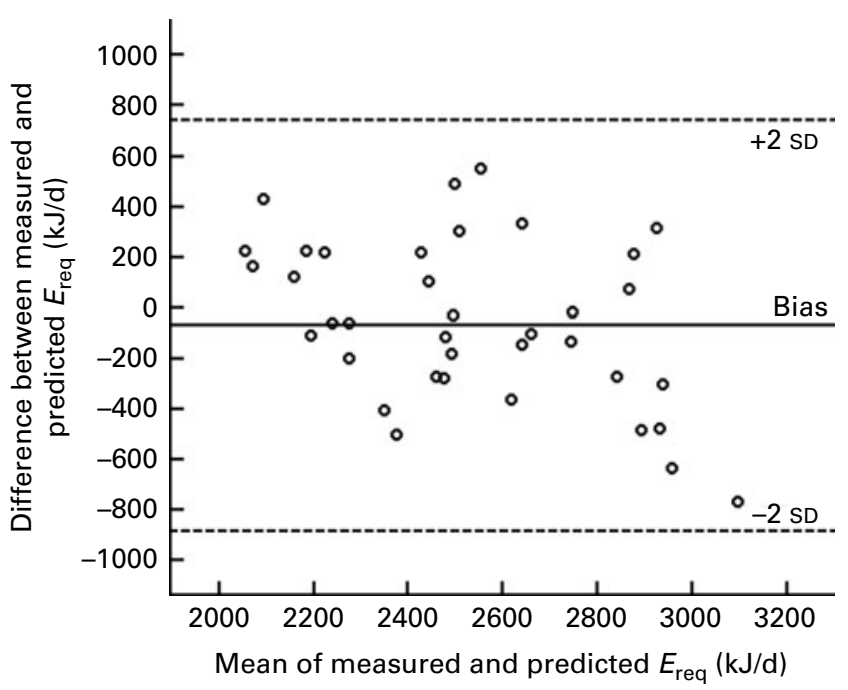

Fig. 4. Bland-Altman plot of the difference between predicted energy requirements ( $E_{\text {req }}$, using a simple multiplier of body weight) and determined $E_{\text {req }}$ (using the factorial approach) $v$. the mean of predicted and determined $E_{\text {req }}$ for the second time point. Bias is indicated by the full line and limits of agreements are indicated by punctured lines. 
ronment. Both socio-economic status within a country as well as provenance in general might influence energy requirements and limit the generalisability of the present study.

The present sample of infants was unique in the sense that only infants who were strictly EBF, as defined by the WHO, were kept in the analysis. Therefore, any variation in data caused by feeding mode was eliminated, and such data have, to our knowledge, not been published previously.

It is common practice in clinical settings to combine a mean reference value per $\mathrm{kg}$ body weight with individual body weight to predict individual energy requirements. For such prediction equations, errors are large and lack of consideration to this might result in over- or under-estimation of energy requirements. Furthermore, in the present study, errors were negatively correlated with energy requirements, suggesting that the underestimation is greater when energy requirements are high. This is important to have in mind whenever prediction equations are used at the individual level, e.g. in the clinical setting. Finally, indications of sufficient growth should always be ascertained, as this remains the most sensitive indicator of whether infant energy requirements are being met.

In summary, TEE was predicted fairly accurately in EBF infants at the population level by using the equation by the $\mathrm{FAO} / \mathrm{WHO} / \mathrm{UNU}^{(10)}$, compared with the criterion method of measured TEE using doubly labelled water. Predicted energy requirements underestimated energy requirements in 3.5-month-old EBF infants by $7 \cdot 2 \%$ at the population level, which is clinically important, compared with the determined energy requirements using the criterion method (the factorial approach). Prediction equations for both TEE and infant energy requirements had errors that were too large for them to predict TEE or energy requirements with confidence at an individual level.

\section{Acknowledgements}

We wish to thank Ms Caroline Haig for help with producing the graphs for the present manuscript. The contributions of the authors were as follows: J. J. R., J. C. K. W. developed the original concept; S. B. N., J. J. R., M. S. F., J. C. K. W. developed the study design and methods; S. B. N. conducted the research and collected all data; S. E., J. G. performed isotope analyses; S. B. N., J. G., J. J. R., J. C. K. W. analysed isotope data and interpreted the results; S. B. N. prepared all drafts of the manuscript; all authors reviewed drafts of the manuscript. The authors had full access to all of the data and the corresponding author takes responsibility for the integrity of the data and the accuracy of the data analysis. The authors have no conflicts of interest to declare. Full disclosures on potential conflicts of interests for all authors are available from the corresponding author (ICMJE forms). The study was funded by the Scottish Government Health Department, S. B. N. received a studentship from The Yorkhill Children's Foundation.

\section{References}

1. WHO (2001) 54th World Health Assembly 2001: Infant and Young Child Nutrition. Geneva: WHO.

2. WHO (2008) Indicators for Assessing Infant and Young Child Feeding Practices. Part 1: Definitions. Geneva: WHO.

3. Butte NF, Lopez-Alarcon MG \& Garza C (2002) Nutrient Adequacy of Exclusive Breastfeeding for the Term Infant during the First Six Months of Life. Geneva: WHO.

4. Reilly JJ \& Wells JC (2005) Duration of exclusive breastfeeding: introduction of complementary feeding may be necessary before 6 months of age. BrJ Nutr 94, 869-872.

5. SACN (2011) Dietary reference values for energy. http:// www.sacn.gov.uk/pdfs/sacn_dietary_reference_values_for_ energy.pdf (accessed 23 May 2012)

6. Nielsen SB, Reilly JJ, Fewtrell MS, et al. (2011) Adequacy of milk intake during exclusive breastfeeding: a longitudinal study. Pediatrics 128, e907-e914.

7. Wells JC, Jonsdottir OH, Hibberd PL, et al. (2012) Randomized controlled trial of 4 compared with 6 mo of exclusive breastfeeding in Iceland: differences in breast-milk intake by stable-isotope probe. Am J Clin Nutr 96, 73-79.

8. Butte NF (2005) Energy requirements of infants. Public Health Nutr 8, 953-967.

9. Lucas A (2005) Long-term programming effects of early nutrition - implications for the preterm infant. J Perinatol 25, Suppl. 2, S2-S6.

10. FAO (2004) Human Energy Requirements. Report of a Joint FAO/WHO/UNU Expert Consultation. Rome: FAO.

11. Butte NF (1996) Energy requirements of infants. Eur J Clin Nutr 50, Suppl. 1, S24-S36.

12. Butte NF, Wong WW, Hopkinson JM, et al. (2000) Infant feeding mode affects early growth and body composition. Pediatrics 106, 1355-1366.

13. Dewey KG (1998) Growth characteristics of breast-fed compared to formula-fed infants. Biol Neonate 74, 94-105.

14. Dewey KG, Peerson JM, Brown KH, et al. (1995) Growth of breast-fed infants deviates from current reference data: a pooled analysis of US, Canadian, and European data sets. World Health Organization Working Group on Infant Growth. Pediatrics 96, 495-503.

15. Whitehead RG \& Paul AA (1984) Growth charts and the assessment of infant feeding practices in the Western world and in developing countries. Early Hum Dev 9, 187-207.

16. Butte NF, Wong WW, Ferlic L, et al. (1990) Energy expenditure and deposition of breast-fed and formula-fed infants during early infancy. Pediatr Res 28, 631-640.

17. Jiang Z, Yan Q, Su Y, et al. (1998) Energy expenditure of Chinese infants in Guangdong Province, south China, determined with use of the doubly labeled water method. $A m \mathrm{~J}$ Clin Nutr 67, 1256-1264.

18. Butte NF, Wong WW, Hopkinson JM, et al. (2000) Energy requirements derived from total energy expenditure and energy deposition during the first $2 \mathrm{y}$ of life. Am J Clin Nutr 72, 1558-1569.

19. Nielsen SB, Wells JC, Slater C, et al. (2011) Administering labelled water to exclusively breast-fed infants in studies involving stable isotope dilution techniques. Isotopes Environ Health Stud $\mathbf{4 7}, 18-25$.

20. Roberts SB \& Lucas A (1985) Measurement of urinary constituents and output using disposable napkins. Arch Dis Child 60, 1021-1024.

21. IAEA (2009) Assessment of Body Composition and Total Energy Expenditure in Humans Using Stable Isotope Techniques. Vienna: International Atomic Energy Agency. 
22. Coelho R, Wells J, Symth J, et al. (2007) Severe hypoinsulinaemic hypoglycaemia in a premature infant associated with poor weight gain and reduced adipose tissue. Horm Res 68, 91-98.

23. Cole TJ \& Coward WA (1992) Precision and accuracy of doubly labeled water energy expenditure by multipoint and two-point methods. Am J Physiol 263, E965-E973.

24. Coward WA, Sawyer MB, Whitehead RG, et al. (1979) New method for measuring milk intakes in breast-fed babies. Lancet ii, 13-14.

25. Weir JB (1949) New methods for calculating metabolic rate with special reference to protein metabolism. I Physiol 109, 1-9.

26. WHO Multicentre Growth Reference Study Group (2006) WHO Child Growth Standards based on length/height, weight and age. Acta Paediatr Suppl 450, 76-85.

27. Whyte RK, Bayley HS \& Schwarcz HP (1985) The measurement of whole body water by $\mathrm{H}_{2}(18) \mathrm{O}$ dilution in newborn pigs. Am J Clin Nutr 41, 801-809.

28. Fomon SJ, Haschke F, Ziegler EE, et al. (1982) Body composition of reference children from birth to age 10 years. $\mathrm{Am} \mathrm{J}$ Clin Nutr 35, 1169-1175.
29. Wells JC \& Davies PS (1998) Estimation of the energy cost of physical activity in infancy. Arch Dis Child 78, 131-136.

30. Bland JM \& Altman DG (1986) Statistical methods for assessing agreement between two methods of clinical measurement. Lancet i, 307-310.

31. Reilly JJ, Kelly LA, Montgomery C, et al. (2006) Validation of actigraph accelerometer estimates of total energy expenditure in young children. Int J Pediatr Obes 1, 161-167.

32. Reilly JJ, Evans TJ, Wilkinson J, et al. (1999) Adequacy of clinical formulae for estimation of energy requirements in children with cystic fibrosis. Arch Dis Child 81, 120-124.

33. Elia M (2005) Insights into energy requirements in disease. Public Health Nutr 8, 1037-1052.

34. Wells JC \& Davies PS (1999) Can body size predict infant energy requirements? Arch Dis Child 81, 429-430.

35. Wells JCK, Hinds A \& Davies PSW (1997) Free-living energy expenditure and behaviour in late infancy. Arch Dis Child 76, 490-494.

36. Wells JC, Williams JE, Haroun D, et al. (2009) Aggregate predictions improve accuracy when calculating metabolic variables used to guide treatment. Am J Clin Nutr 89, 491-499. 